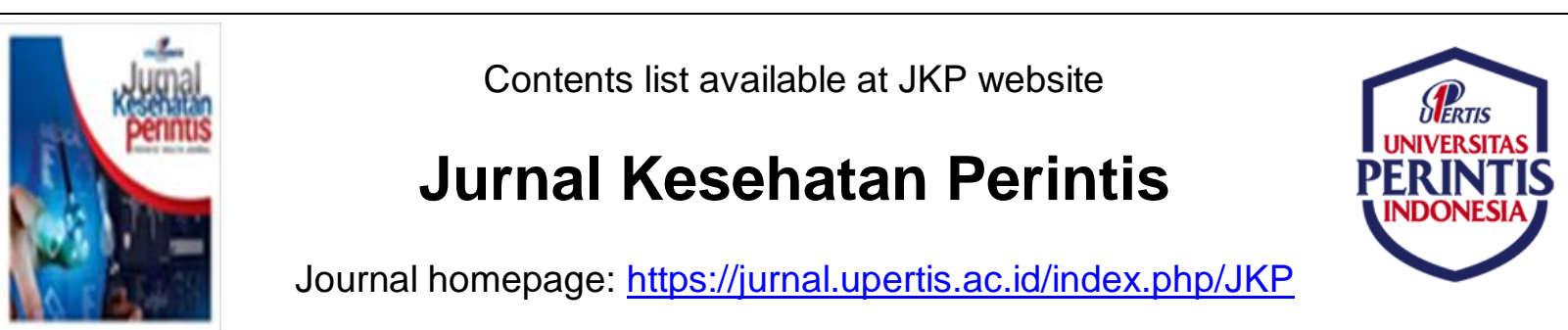

\title{
Peran Kader Terhadap Pemberian Kapsul Vitamin A Pada Balita
}

\author{
Fanny Ayudia, Amrina Amran, Arfianingsih Dwi Putri \\ Sekolah Tinggi Ilmu Kesehatan Alifah Padang, Sumatera Barat, Indonesia
}

\section{Article Information :}

Submission: Sept 30, 2021; Revised:Dec 09, 2021; Accepted:Dec 30, 2021; Available online: Dec 31,2021

*Corresponding author : fannyayudia@yahoo.co.id

\begin{abstract}
ABSTRAK
Pemberian kapsul Vitamin A sangat penting untuk menjaga kesehatan terutama kesehatan untuk mata yang dapat mencegah kebutaan dan lebih penting lagi untuk meningkatkan daya tahan tubuh. Pemberian vitamin A yang cukup pada anak dapat mencegah atau mengurangi keparahan suatu penyakit yang diderita anak seperti diare, campak atau penyakit infeksi seperti ISPA, sehingga tidak membahayakan jiwa anak. Profil Dinas Kesehatan Propinsi Sumatera Barat Tahun 2014 Balita yang diberi vitamin A sebanyak 60.385 (85,7\%), sedangkan target Dinas Kesehatan Kota Padang sebesar 100\%. Peran petugas kesehatan di masyarakat harus memberikan penyuluhan kepada masyarakat mengenai vitamin $A$, karena dengan adanya peran petugas kesehatan sebagai vasilitator akan meningkatkan pengetahuan ibu mengenai vitamin A.Tujuan penelitian ini untuk mengetahui hubungan peran kader terhadap pemberian kapsul vitamin A pada balita. Jenis dan desain penelitian ini analitik dengan menggunakan cross sectional study. Populasi pada penelitian ini adalah ibu yang memiliki anak balita dengan sampel sebanyak 90 orang. Analisis penelitian ini menggunakan uji Chi-Square pada derajat kemaknaan $95 \%(\alpha=$ $0,05)$. Hasil pada penelitian ini terdapat $74,5 \%$ Kader yang tidak berperan dalam pemberian kapsul vitamin A pada balita. Setelah dilakukan uji statistik didapatkan hasil bahwa terdapat hubungan antara peran kader dengan pemberian kapsul vitamin A pada balita dengan nilai $p$ value $=0,001 \quad(p<0,05$. Penelitian ini menunjukkan bahwa kader dapat berperan dalam memberikan penyuluhan kepada ibu yang memiliki balita dengan harapan ibu yang memiliki balita membawa anaknya untuk mendapatkan vitamin A. Disarankan kepada puskesmas yang berada di kota Padang agar diberikan pelatihan kader tentang pemberian vitamin $\mathrm{A}$.
\end{abstract}

Kata kunci : balita, kader, vitamin A

\section{ABSTRACT}

Giving Vitamin A capsules is very important to maintain health, especially eye health which can prevent blindness and more importantly to increase endurance. Giving sufficient vitamin A to children can prevent or reduce the severity of a disease suffered by children such as diarrhea, measles or infectious diseases such as ARI, so it does not endanger the child's li. Profile of the Health Office of West Sumatra Province in 2014 Toddlers who were given vitamin A were 60,385 (85.7\%), while the target of the Padang City Health Service was $100 \%$. The role of health workers in the community must provide counseling to the community about vitamin $A$, because the role of health workers as facilitators will increase mother's knowledge about vitamin A. The type and design of this research is analytic by 
using a cross sectional study. The population in this study were mothers who had children under five with a sample of 90 people. The analysis of this study used the Chi-Square test at a significance level of $95 \%(\alpha=0.05)$. The results in this study were $74.5 \%$ of cadres who did not play a role in giving vitamin A capsules to toddlers. After statistical tests were carried out, the results showed that there was a relationship between the role of cadres and the provision of vitamin A capsules to toddlers with a $p$ value $=0.001(p<0.05$. This study shows that cadres can play a role in providing counseling to mothers who have toddlers with the hope of mothers who have toddlers bring their children to get vitamin A. It is recommended to the puskesmas in the city of Padang to be given cadre training on the administration of vitamin $A$.

Keywords: toddler, cadres, vitamin A

\section{PENDAHULUAN}

Kurang Vitamin A (KVA) pada ibu dan Balita di Indonesia masih terjadi peningkatan. Beberapa provinsi di Indonesia masih ditemukan kasus-kasus baru KVA yang terjadi pada anak penderita gizi buruk. sehingga KVA masih perlu mendapatkan perhatian dan penanganan secara serius. (Rodriguez, L,et al, 2011)).

Berdasarkan Riskesdas tahun 2013 data cakupan pemberian suplementasi vitamin A pada anak 12-59 sebesar $75,5 \%$, sedangkan The Lancet Series, Maternal and Child Nutrition, 2013 merekomendasikan cakupan harus lebih dari $90 \%$ agar effektifitas program optimal. Untuk meningkatkan permintaan masyarakat terhadap suplementasi vitamin A diperlukan intensifikasi pemberdayaan masyarakat. Pemberian kapsul vitamin A merupakan salah satu indikator keberhasilan gerakan 1000 hari pertama kehidupan sehingga perlu diimplementasikan dengan baik agar cakupan pemberian mencapai target (Agustyani.FT, 2012).

Promosi dan pemberdayaan masyarakat merupakan bagian yang sangat penting dalam meningkatkan partisipasi masyarakat yang efektif. Pemberdayaan memberikan kontribusi yang penting untuk terciptanya mobilisasi dan partisipasi yang efektif dalam masyarakat (Zuliani,2011). Promosi dilakukan melalui penyebarluasan informasi khususnya tentang vitamin $\mathrm{A}$ dan program terpadu lainnya, hal ini perlu dilakukan sebelum bulan kapsul (Februari dan Agustus), dengan tujuan untuk meningkatkan cakupan pemberian kapsul vitamin $A$ yang melibatkan unsur masyarakat dan keluarga (Kemenkes, 2016).
Kader sangat berperan dimasyarakat dalam memberikan penyuluhan kepada masyarakat mengenai vitamin $A$, karena dengan adanya peran kader sebagai vasilitator akan meningkatkan pengetahuan ibu mengenai vitamin A (Fazria.J.T, 2012).

Hasil penelitian Yuliarti, tahun 2016, menemukan bahwa $74 \%$ ibu yang memiliki balita didapatkan kurangnya pengetahuan ibu tentang vitamin $A$ dan penelitian Indrawati, 2014 lebih dari separoh ibu yang memiliki pengetahuan rendah tentang vitamin A. Ini membuktikan bahwa pengetahuan ibu terhadap pengertian, manfaat, sumber, serta jadwal pemberian kapsul vitamin A berhubungan dengan cakupan pemberian vitamin A. Ibu yang memiliki kesadaran akan pentingnya pemberian vitamin A pada balita terlihat dari pengetahuan yang dimiliki (Herawati, 2014). Penelitian ini berbeda dengan penelitian yang saya lakukan bahwa untuk meningkatkan pengetahuan ibu maka diperlukan peran kader dalam memberikan informasi tentang vitamin A kepada ibu .

Dinas Kesehatan Provinsi Sumatera Barat tahun 2018 mengemukakan bahwa dari 98,174 bayi hanya $77.96 \%$ yang mendapatkan vitamin A. Cakupan pemberian vitamin A di Dinas Kesehatan Kota Padang tahun 2019 mengemukakan bahwa terjadi penurunan pemberian vitamin A pada bayi $6-11$ bulan yakni dari $82,73 \%$ di tahun 2015 menjadi $80,26 \%$ di tahun 2016 (DKK Padang, 2016), Pada tahun 2017 meningkat sebesar $84,30 \%$ dan kembali menurun 83,28 \% ditahun 2018 (DKK Padang, 2019). Tujuan dari penelitian ini adalah untuk mengetahui hubungan peran kader terhadap pemberian kapsul vitamin A pada balita. 


\section{METODE PENELITIAN}

Jenis penelitian ini merupakan penelitian analitik dengan menggunakan desain cross sectional study. Populasi pada penelitian ini adalah ibu yang memiliki anak balita dengan sampel dalam penelitian ini sebanyak 90 orang.Teknik pengambilan sampel pada penelitian ini menggunakan sistematik random sampling. Pengumpulan data menggunakan kuesioner sebanyak 20 soal. Kuesioner dinyatakan valid dan reliabel dengan nilai uji validitas $r$ hitung (Corrected Item-Total Correlation) $>r$ tabel sebesar 0,378 dan nilai uji reabilitas sebesar rll $=0,907$ nilai "Alpha Cronbach" lebih besar dari 0,600. Analisis penelitian ini menggunakan uji statistik Chi-Square pada derajat kemaknaan 95\% $(\alpha=0,05)$. Dalam mengambil keputusan uji statistik digunakan batas bermakna 0,05.

\section{HASIL DAN PEMBAHASAN}

Gambaran distribusi frekuensi pemberian kapsul vitamin A pada balita dapat dilihat pada gambar 1 yang menunjukkan bahwa lebih dari separuh responden yaitu sebanyak 47 orang $(52,42 \%)$ balitanya tidak diberikan vitamin A. Ibu yang sebagian besar ibu rumah tangga akan banyak memiliki waktu untuk mengajak anaknya ke posyandu untuk menimbang berat badan dan mendapatkan kapsul vitamin A (Kusumaningrum, S, 2011).

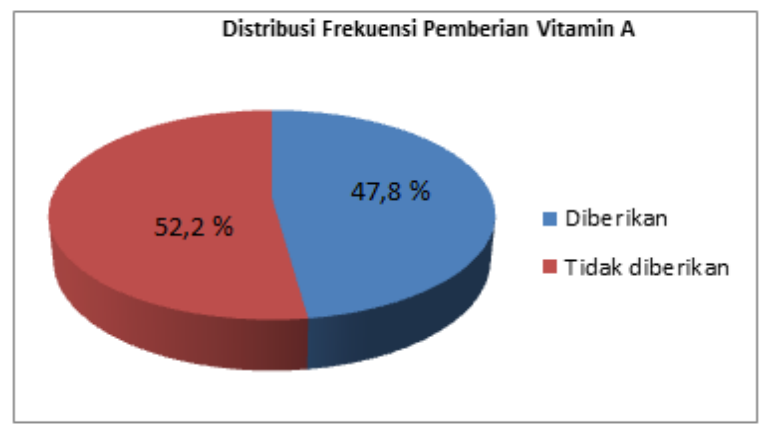

\section{Gambar 1. Pemberian Vitamin A pada Balita}

Gambaran Peran kader dapat dilihat pada gambar 2 yang menunjukkan bahwa lebih dari separuh responden yaitu sebanyak 47 orang $(52,2 \%)$ menganggap peran kader tergolong kurang aktif.
Salah satu penyebab kurang aktifnya peran kader disebabkan karena motivasi kader yang rendah dan juga upah kader yang tidak seberapa sehingga menyebabkan kder menjadi jenuh dalam dalam kegiatan posyandu yang mempengaruhi mnat ibu membawa balita untuk mendapatkan vitamin A (Sunarti, H, dkk, 2019)

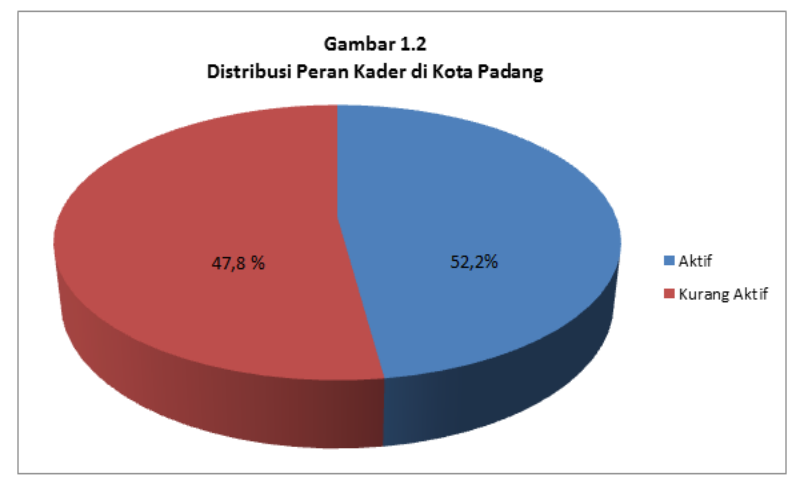

\section{Gambar 2. Peran Kader dalam pemberian Vitamin A}

Berdasarkan hasil penelitian, dari 47 responden terdapat $74,5 \%$ kader berperan kurang aktif dalam pemberian vitamin $A$ pada balita, sebaliknya dari 43 responden $72,1 \%$ kader memiliki peran yang aktif dalam pemberian kapsul vitamin A. Setelah dilakukan uji statistik didapatkan nilai $p$ value $=0,001 \quad(p<0,05)$, ini berarti ada hubungan peran kader dengan pemberian kapsul vitamin A pada balita di kota Padang (tabel 1).

Penelitian ini sejalan dengan penelitian Hanapi (2019) yang mengatakan bahawa salah satu faktor yang mempenagruhi keberhasilan pemberian vitamin A pada balita adalah peran kader (Hanapi, 2019). Selaian itu penelitian Elisabet (2021) juga menunjukkan bahwa pengetahuan kader mempengaruhi perilaku kader dalam pemberian Vitamin A pada balita (Elisabet, 2021).

Kader Posyandu merupakan kader pembangunan kesehatan yang mana dipilih dan mendapat kepercayaan dari masyarakat dan telah mendapatkan pelatihan khusus dari puskesmas setempat untuk melaksanakan, memelihara dan mengembangkan kegiatan posyandu yang ada didaerahnya secara sukarela. Peran kader dalam pemberian vitamin A seperti memberitahukan jadwal pemberian vitamin

A, manfaat vitamin A pada balita dan akibat kekurangan vitamin A (Depkes RI, 2012) 
Tabel 1. Peran Kader terhadap pemberian vitamin A

\begin{tabular}{lccccccc}
\hline Peran Kader & \multicolumn{2}{c}{$\begin{array}{c}\text { Pemberian Kapsul Vitamin A } \\
\text { Tidak Diberikan }\end{array}$} & \multicolumn{2}{c}{ Diberikan } & \multicolumn{2}{c}{ Total } & \multicolumn{2}{c}{ P Valaue } \\
& f & $\%$ & $\mathbf{f}$ & $\%$ & F & $\%$ & \\
\hline Kurang Aktif & 35 & 74,5 & 12 & 25,5 & 47 & 100 & \\
Aktif & 12 & 27,9 & 31 & 72,1 & 43 & 100 & 0,001 \\
Jumlah & 47 & 52,2 & 43 & 47,8 & 90 & 100 & \\
\hline
\end{tabular}

Peran Kader merupakan salah satu upaya pemerintah dalam memberdayakan masyarakat untuk menurunkan angka kematian bayi dan balit, dan meningkatkan taraf kesehatan masyarakat (Noeralim, DN ,2017). Kader masih banyak yang belum

Motivasi Kader rendah atau kader menjadi jenuh dalam kegiatan posyandu maka bisa menyebabkan kader drop out seperti yang kita ketahui bahwa menjadi kader merupakan pekerjaan ssial yang tidak mempunyai kekuatan mengikat sehingga mereka menjadi leluasa untuk keluar menjadi kader apalagi ditambah

masyarakat dan kader posyandu tentang vitamin A merupakan solusi dalam meningkatkan kesadaran masyarakat tentang pemberian kapsul vitamin A (Kemenkes, 2016).

Kader merupakan orang yang dekat dengan ibu balita, oleh sebab itu perlu di peran aktif kader dalam memberikan berbagai informasi kepada balita mengenai vitamin A. Perlu ditingkatkan pengetahuan kader dengan cara memberikan pelatihanpelatihan mengenai vitamin A (Astuti, EP, 2013).

\section{KESIMPULAN}

Penelitian ini menunjukkan terdapat hubungan peran kader terhadap pemberian kapsul vitamin A pada balita di Kota Padang. Kader dapat berperan dalam memberikan penyuluhan kepada ibu yang memiliki balita sehingga cakupan pemberian vitamin A dapat tercapai dengan baik.

\section{REFERENSI}

Astuti E.P, (2013) Faktor-faktor yang mempengaruhi pemberian Vitamin A Pada Balita di Posyandu Dayu Makmur Sleman.

DKK Padang. (2018). Profil Kesehatan Kota berperan dalam pemberian kapsul vitamin A pada balita, kurangnya keaktifan kader menyebabkan minimnya ibu balita memperoleh pengetahuan mengenai vitamin $A$ dan jadwal pemberian kapsul vitamin A (Indarwati E, 2014).

regenerasi kader yang belum terencana dengan baik (Rozak A.M, 2011).

Rendahnya cakupan suplementasi vitamin A ini mengindikasikan bahwa manajemen dan pemberdayaan dalam program suplementasi vitamin A tingkat kabupaten dan kota belum berjalan optimal (Dwiana P, 2014) . Meningkatkan pengetahuan

Padang Tahun 2018, 1-117.

Dinas Kesehatan Kota Padang. 2012 Profil Kesehatan. Padang

Dwiana Putri, (2014). Hubungan Tingkat Pengetahuan lbu dengan upaya Pemberian Kapsul Vitamin A Pada BAlita di PuskesmasWirobrajan Yogyakarta.

Elisabet Belinda meliana, Dian Ayubi (2021). Hubungan pengetahuan, sikap dengan perilaku kader posyandu dalam pelaksanaan pemberian vitamin $\mathrm{A}$ di Jakarta Timur. Jurnal IImiah Kesehatan vol 13(1): Maret 2021.Doi : https://doi.org/10.37012/JIK.V13I1.447

Fazria, J.T, 2012. Tingkat pengetahuan lbu Tentang Vitamin A Pada Balita Dipolindes. Singosari, Mojosongo, Boyolali, Surakarta : STIKes Kusuma Husada

Hanap sunarti, Nuryani Nuryani, Rahmawaty Ahmad (2019). Sejumlah Faktor yang Berhubungan dengan Pemberian Vitamin A pada Balita. Gorontalo Journal of Public Health. Vol 2 no 2 2019. doi: https://doi.org/10.32662/gjph.v2i2.751

Herawati.(2014). Perilaku Tenaga Kesehatan Dalam Memberikan Pendidikan Kesehatan dengan Perilaku 
Ibu dalam Pemberian Kapsul Vitamin A Pada anak Berusia 6-59 Bulan. Retrieved

fromhttps://www.geogle.co.id/sea

rch?q=724-1513-1-

SM46957660.39004.pdf

Indarwati, E. (2014). Hubungan Tingkat Pengetahuan lbu dengan Cakupan Pemberian Vitamin A Pada Balita DI PKD Melati Sari Desa Duren sari Kecamatan Bagelan Kabupaten Purwerejo. Retrieved from https://www.google.co.id/jurnaljkk10769i57.103604.pdf

Kusumaningrum, S (2011) Gambaran tingkat pengetahuan lbu tentang Pemberian Vitamin A Dosis Tinggi pada lbu yang mempunyai Balita di Posyandu Purna Yuda Wilayah Kerja Puskesmas Banyu Urip Kabupaten Purwarejo

Kemenkes, (2016) Panduan Manajemen Terintegrasi Suplementasi Vitamin A.

Noeralim, DN, 2017. Faktor-faktor yang berhubungan dengan keaktifan kunjungan ibu Balita ke Posyandu.

Rodríguez, L., Cervantes, E., \& Ortiz, R.
(2011). Malnutrition and gastrointestinal and respiratory infections in children: A public health problem.International Journal of Environmental Research and Public Health. 8 (4), 1174-1205. doi: 10.3390/ijerph8041174

Rozak, A.M, 2011. Faktor-faktor yang berhubungan dengan kunjungan balita di Posyandu Wilayah Kerja Puskesman Antara Makasar.

Sunarti Hanapi, Nuryani, Rahmawati Ahmad, 2019. Sejumlah Faktor yang berhubungan dengan Pemberian Vitamin A pada Balita

Yuliarti.Y. (2016). Hubungan Sikap lbu dengan Pemberian Vitamin A pada BalitaUsia 12-59 Bulan di Puskesmas Rumbai Pesisir Kota Pekanbaru Tahun 2016. KTI AKBID Helvetia, Pekanbaru.

Zuliani. (2011). Pemahaman Tentang Kapsul Vitamin A serta Akibat Kekurangan Vitamin A. https://elvizulianisehatidotcom.fi les.wordpress.com/2011/07/kura ngvitamin-a.pdf 